Pacific Journal of Mathematics

FIXED POINT THEOREMS FOR SET-VALUED MAPPINGS OF 


\title{
FIXED POINT THEOREMS FOR SET-VALUED MAPPINGS OF CONTRACTIVE TYPE
}

\author{
NADIM A. AsSAD AND W. A. KIRK
}

\begin{abstract}
In this paper a new fixed point theorem is proved for contraction mappings in a complete metric space by observing that if the space is metrically convex, then significant weakenings may be made concerning the domain and range of the mapping considered. While the main theorem is formulated for set-valued mappings, its point-to-point analogue is also a new result. This result, proved in $\S 1$, is the following: Suppose $M$ is a complete, metrically convex, metric space, $K$ a nonempty closed subset of $M$, and $\varphi$ a contraction mapping from $K$ into the family $\mathscr{T}(M)$ of nonempty closed bounded subsets of $M$ supplied with the Hausdorff metric. Then if $\varphi$ maps the boundary of $K$ into subsets of $K, \varphi$ has a fixed point in $K$, i.e., there is a point $x_{0} \in K$ such that $x_{0} \in \varphi\left(x_{0}\right)$.
\end{abstract}

Many applications of the contraction mapping theorem occur in a convex setting, and in particular the results of this paper are applied to obtain new fixed point theorems in Banach spaces. For example, if $H$ is a closed convex subset of a Banach space $X$ and $T$ is a contraction mapping of $K$ into $H$ where $K$ is a nonempty closed subset of $H$, then the requirement that $T$ maps the boundary of $K$ relative to $H$ back into $K$ is sufficient to guarantee a fixed point for $T$. Hypotheses of this type are not new in analysis; for mappings which are completely continuous, $H$ is often taken as the positive cone in $X$ and $K$ the intersection of $H$ with the closed unit ball.

In $\S 2$ we use the above theorem to obtain an improved version of Lami Dozo's generalization [9] of a theorem of J. Markin [10], and in $\S 3$ a connection between fixed point theory of Lipschitzian pseudo-contractive mappings and that of nonexpansive mappings yields a theorem which generalizes results of Kirk [7], [8].

1. Set-valued contraction mappings. Let $(M, d)$ be a metric space and let $\mathscr{T}(M)$ denote the family of all nonempty bounded closed subsets of $M$. For $A, B \in \mathscr{T}(M)$, let $D(A, B)$ denote the distance between $A$ and $B$ in the Hausdorff metric induced by $d$ on $\mathscr{T}(M)$. In particular, if for $r>0$ and $E \in \mathscr{T}(M)$ we define

$$
V_{r}(E)=\{x \in M: \operatorname{dist}(x, E)<r\},
$$

then we have

$$
D(A, B)=\inf \left\{r: A \subset V_{r}(B) \text { and } B \subset V_{r}(A)\right\} .
$$


In the theorem below we shall assume $M$ is a complete metric space which is (metrically) convex, that is, $M$ has the property that for each $x, y \in M$ with $x \neq y$ there exists $z \in M, x \neq z \neq y$, such that

$$
d(x, z)+d(z, y)=d(x, y) .
$$

K. Menger has shown that in such a space each two points are the endpoints of at least one metric segment. (A proof of this theorem due to N. Aronszajn may be found in L. M. Blumenthal's book [1, p. 41].) This fact immediately yields the following:

REMARK. If $K$ is a closed subset of the complete and convex metric space $M$ and if $x \in K, y \notin K$, then there exists a point $z$ in the boundary of $K$ such that

$$
d(x, z)+d(z, y)=d(x, y) .
$$

We shall also make use of the following lemmas, which are noted implicitly in Nadler [11]. Here $M$ denotes a metric space and $\mathscr{T}(M)$ the family of nonempty bounded closed subsets of $M$.

Lemma 1. If $A, B \in \mathscr{T}(M)$ and $\bar{x} \in A$, then for each positive number $\alpha$ there exists $y \in B$ such that

$$
d(\bar{x}, y) \leqq D(A, B)+\alpha .
$$

LEMMA 2. Let $\left\{A_{n}\right\}$ be a sequence of sets in $\mathscr{T}(M)$, and suppose $\lim _{n \rightarrow \infty} D\left(A_{n}, A_{0}\right)=0$ where $A_{0} \in \mathscr{T}(M)$. Then if $x_{n} \in A_{n}, n=1,2, \cdots$, and if $\lim _{n \rightarrow \infty} x_{n}=x_{0}$, it follows that $x_{0} \in A_{0}$.

In the theorem below we consider a mapping $\varphi$ on a subset $K$ of $M$ which takes values in $\mathscr{T}(M)$. Such a mapping is called a contraction mapping if there exists a constant $k<1$ such that $D(\varphi(x)$, $\varphi(y)) \leqq k d(x, y)$. Also, we use the symbol $\partial K$ to denote the boundary of $K$.

THeOREM 1. Let $M$ be a complete and convex metric space, $K a$ nonempty closed subset of $M$, and $\varphi$ a contraction mapping from $K$ into $\mathscr{T}(M)$. If $\varphi(x) \subset K$ for each $x \in \partial K$ then there exists $x_{0} \in K$ such that $x_{0} \in \varphi\left(x_{0}\right)$ (i.e., $\varphi$ has a fixed point in $K$ ).

Proof. Let $\alpha, 0<\alpha<1$, denote the Lipschitz constant of $\varphi$. We select a sequence $\left\{p_{n}\right\}$ in $K$ in the following way: Let $p_{0} \in K$ and $p_{1}^{\prime} \in \varphi\left(p_{0}\right)$. If $p_{1}^{\prime} \in K$, let $p_{1}=p_{1}^{\prime}$; otherwise select a point $p_{1} \in \partial K$ such that $d\left(p_{0}, p_{1}\right)+d\left(p_{1}, p_{1}^{\prime}\right)=d\left(p_{0}, p_{1}^{\prime}\right)$. Thus $p_{1} \in K$ and by Lemma 1 we may choose $p_{2}^{\prime} \in \varphi\left(p_{1}\right)$ so that 


$$
d\left(p_{1}^{\prime}, p_{2}^{\prime}\right) \leqq D\left(\varphi\left(p_{0}\right), \varphi\left(p_{1}\right)\right)+\alpha .
$$

Now put $p_{2}^{\prime}=p_{2}$ if $p_{2}^{\prime} \in K$; otherwise let $p_{2}$ be a point of $\partial K$ such that $d\left(p_{1}, p_{2}\right)+d\left(p_{2}, p_{2}^{\prime}\right)=d\left(p_{1}, p_{2}^{\prime}\right)$. By induction we may obtain sequences $\left\{p_{n}\right\},\left\{p_{n}^{\prime}\right\}$ such that for $n=1,2, \cdots$,

(i) $p_{n+1}^{\prime} \in \varphi\left(p_{n}\right)$,

(ii) $d\left(p_{n+1}^{\prime}, p_{n}^{\prime}\right) \leqq D\left(\varphi\left(p_{n}\right), \varphi\left(p_{n-1}\right)\right)+\alpha^{n}$

where

(iii) $p_{n+1}^{\prime}=p_{n+1}$ if $p_{n+1}^{\prime} \in K$, or

(iv) $d\left(p_{n}, p_{n+1}\right)+d\left(p_{n+1}, p_{n+1}^{\prime}\right)=d\left(p_{n}, p_{n+1}^{\prime}\right)$ if $p_{n+1}^{\prime} \notin K$.

Now let

$$
\begin{aligned}
& P=\left\{p_{i} \in\left\{p_{n}\right\}: p_{i}=p_{i}^{\prime}, i=1,2, \cdots\right\} \\
& Q=\left\{p_{i} \in\left\{p_{n}\right\}: p_{i} \neq p_{i}^{\prime}, i=1,2, \cdots\right\}
\end{aligned}
$$

Observe that if $p_{n} \in Q$ for some $n$, then $p_{n+1} \in P$.

Now for $n \geqq 2$ we consider the distance $d\left(p_{n}, p_{n+1}\right)$. Three cases must be considered:

Case 1. $p_{n} \in P$ and $p_{n+1} \in P$ : In this case we have

$$
\begin{aligned}
d\left(p_{n}, p_{n+1}\right)=d\left(p_{n}^{\prime}, p_{n+1}^{\prime}\right) & \leqq D\left(\varphi\left(p_{n}\right), \varphi\left(p_{n-1}\right)\right)+\alpha^{n} \\
& \leqq \alpha d\left(p_{n}, p_{n-1}\right)+\alpha^{n} .
\end{aligned}
$$

Case 2. $p_{n} \in P$ and $p_{n+1} \in Q$ : Here we use (iv) to obtain

$$
\begin{aligned}
d\left(p_{n}, p_{n+1}\right) & \leqq d\left(p_{n}, p_{n+1}^{\prime}\right) \\
& =d\left(p_{n}^{\prime}, p_{n+1}^{\prime}\right) \\
& \leqq D\left(\varphi\left(p_{n-1}\right), \varphi\left(p_{n}\right)\right)+\alpha^{n} \\
& \leqq \alpha d\left(p_{n-1}, p_{n}\right)+\alpha^{n} .
\end{aligned}
$$

Case 3. $p_{n} \in Q$ and $p_{n+1} \in P$ : By the above observation, two consecutive terms of $\left\{p_{n}\right\}$ cannot be in $Q$, hence $p_{n-1} \in P$ and $p_{n-1}^{\prime}=p_{n-1}$. Using this below, we obtain

$$
\begin{aligned}
d\left(p_{n}, p_{n+1}\right) & \leqq d\left(p_{n}, p_{n}^{\prime}\right)+d\left(p_{n}^{\prime}, p_{n+1}\right) \\
& =d\left(p_{n}, p_{n}^{\prime}\right)+d\left(p_{n}^{\prime}, p_{n+1}^{\prime}\right) \\
& \leqq d\left(p_{n}, p_{n}^{\prime}\right)+D\left(\varphi\left(p_{n-1}\right), \varphi\left(p_{n}\right)\right)+\alpha^{n} \\
& \leqq d\left(p_{n}, p_{n}^{\prime}\right)+\alpha d\left(p_{n-1}, p_{n}\right)+\alpha^{n} \\
& <d\left(p_{n-1}, p_{n}^{\prime}\right)+\alpha^{n} \\
& =d\left(p_{n-1}^{\prime}, p_{n}^{\prime}\right)+\alpha^{n} \\
& \leqq D\left(\varphi\left(p_{n-2}\right), \varphi\left(p_{n-1}\right)\right)+\alpha^{n-1}+\alpha^{n} \\
& \leqq \alpha d\left(p_{n-2}, p_{n-1}\right)+\alpha^{n-1}+\alpha^{n} .
\end{aligned}
$$


The only other possibility, $p_{n} \in Q, p_{n+1} \in Q$, cannot occur. Thus for $n \geqq 2$ we have

$$
d\left(p_{n}, p_{n+1}\right) \leqq\left\{\begin{array}{l}
\alpha d\left(p_{n}, p_{n-1}\right)+\alpha^{n}, \text { or } \\
\alpha d\left(p_{n-2}, p_{n-1}\right)+\alpha^{n}+\alpha^{n-1}
\end{array} .\right.
$$

Now let $\delta=\alpha^{-1 / 2} \max \left\{d\left(p_{0}, p_{1}\right), d\left(p_{1}, p_{2}\right)\right\}$.

Assertion. For $n \geqq 1$,

$$
d\left(p_{n}, p_{n+1}\right) \leqq \alpha^{n / 2}(\delta+n) .
$$

In order to prove this by induction we must establish the cases $n=$ 1,2. For $n=1$

$$
d\left(p_{1}, p_{2}\right) \leqq \alpha^{1 / 2} \delta<\alpha^{1 / 2}(\delta+1) .
$$

For $n=2$ we use $\left(^{*}\right)$ and take each case separately.

$$
\begin{aligned}
d\left(p_{2}, p_{3}\right) & \leqq \alpha d\left(p_{1}, p_{2}\right)+\alpha^{2} \\
& \leqq \alpha\left(\alpha^{1 / 2} \delta+\alpha\right) \\
& \leqq \alpha(\delta+2) ; \\
d\left(p_{2}, p_{3}\right) & \leqq \alpha d\left(p_{0}, p_{1}\right)+\alpha^{2}+\alpha \\
& \leqq \alpha\left(\alpha^{1 / 2} \delta+\alpha+1\right) \\
& \leqq \alpha(\delta+2) .
\end{aligned}
$$

Now assume $\left({ }^{* *}\right)$ holds for $1 \leqq n \leqq N$, and for $N \geqq 2$ consider the two cases:

$$
\text { 1. } \begin{aligned}
d\left(p_{N+1}, p_{N+2}\right) & \leqq \alpha d\left(p_{N}, p_{N+1}\right)+\alpha^{N} \\
& \leqq \alpha\left[\alpha^{N / 2}(\delta+N)\right]+\alpha^{N} \\
& \leqq \alpha^{(N+1) / 2} \delta+(N+1) \alpha^{(N+2) / 2} \\
& \leqq \alpha^{(N+1) / 2}(\delta+(N+1)) .
\end{aligned}
$$

2. $d\left(p_{N+1}, p_{N+2}\right) \leqq \alpha d\left(p_{N-1}, p_{N}\right)+\alpha^{N+1}+\alpha^{N}$

$$
\begin{aligned}
& \leqq \alpha\left[\alpha^{(N-1) / 2}(\delta+(N-1))\right]+\alpha^{N+1}+\alpha^{N} \\
& \leqq \alpha^{(N+1) / 2} \delta+(N-1) \alpha^{(N+1) / 2}+\alpha^{N+1}+\alpha^{N} \\
& \leqq \alpha^{(N+1) / 2}(\delta+(N+1)) .
\end{aligned}
$$

This proves the assertion, and from $\left({ }^{* *}\right)$ it follows that

$$
d\left(p_{k}, p_{N}\right) \leqq \delta \sum_{i=N}^{\infty}\left(\alpha^{1 / 2}\right)^{i}+\sum_{i=N}^{\infty} i\left(\alpha^{1 / 2}\right)^{i}, \quad k>N \geqq 1 .
$$

This implies $\left\{p_{n}\right\}$ is a Cauchy sequence and since $M$ is complete and $K$ closed, $\left\{p_{n}\right\}$ converges to a point $x_{0} \in K$. Also observe that there exists a subsequence $\left\{p_{n_{k}}\right\}$ of $\left\{p_{n}\right\}$ each of whose terms is in the set 
$P$ (i.e., $\left.p_{n_{k}}=p_{n_{k}}^{\prime}, k=1,2, \cdots\right)$. Thus by (i), $p_{n_{k}}^{\prime} \in \varphi\left(p_{n_{k}-1}\right), k=1,2$, $\cdots$, and since $p_{n_{k-1}} \rightarrow x_{0}$ as $k \rightarrow \infty$ we have $\varphi\left(p_{n_{k-1}}\right) \rightarrow \varphi\left(x_{0}\right)$ as $k \rightarrow \infty$ in the Hausdorff metric. It follows from Lemma 2 that $x_{0} \in \varphi\left(x_{0}\right)$, completing the proof.

REMARK. In the above proof the rate at which the sequence $\left\{p_{n}\right\}$ converges to a fixed point of $\varphi$ is obtainable from $\left(^{* * *}\right)$. If $\varphi$ is a point-to-point mapping then one can always take $p_{n}^{\prime}=\varphi\left(p_{n-1}\right)$ in defining the sequence $\left\{p_{n}\right\}$ thus obtaining in place of (ii)

$$
d\left(p_{n+1}^{\prime}, p_{n}^{\prime}\right)=d\left(\varphi\left(p_{n}\right), \varphi\left(p_{n-1}\right)\right) .
$$

Using this one obtains, in place of $\left({ }^{* *}\right)$, the sharper estimate

$$
d\left(p_{k}, p_{N}\right) \leqq \delta \sum_{i=N}^{\infty}\left(\alpha^{1 / 2}\right)^{i}, \quad k>N \geqq 1 .
$$

For subsets $K, H$ of a Banach space we use the symbol $\partial_{H} K$ to denote the boundary of $K$ relative to $H$. In particular, if $K$ is closed.

$$
\partial_{H} K=\{z \in K: U(z, r) \cap H \backslash K \neq \varnothing \text { for each } r>0\},
$$

where $U(z, r)=\{x \in X:\|z-x\|<r\}$.

By taking $M=H$ in Theorem 1 we obtain:

CoRollary 1. Let $X$ be a Banach space, $H$ a closed convex subset of $X$, and $K$ a closed subset of $H$. If $\phi: K \rightarrow \mathscr{T}(H)$ is a contraction mapping such that $\varphi(x) \subset K$ when $x \in \partial_{H} K$, then there exists $x_{0} \in K$ such that $x_{0} \in \varphi\left(x_{0}\right)$.

Corollary 2. Let $K$ and $H$ be as in Corollary 1. If $T: K \rightarrow$ $H$ is a contraction mapping, and if $T x \in K$ when $x \in \partial_{H} K$, then $T$ has $a$ (unique) fixed point in $K$.

Both of these corollaries are used in the subsequent sections.

2. An approach of Lami Dozo. In [12] Opial observed that every uniformly convex Banach space which possesses a weakly continuous duality mapping [3] satisfies the condition:

(A) If the sequence $\left\{x_{n}\right\}$ is weakly convergent to $x_{0}$, and if $x \neq$ $x_{0}$, then

$$
\liminf _{n \rightarrow \infty}\left\|x_{n}-x\right\|>\liminf _{n \rightarrow \infty}\left\|x_{n}-x_{0}\right\| \text {. }
$$

Following Lami Dozo [9], we say that a Banach space satisfies Opial's condition if it has property (A). Such spaces include Hilbert spaces, and the spaces $l^{p}, 1<p<\infty$ (see Browder [3]). 
For a Banach space $X$, let $\mathscr{K}(X)$ denote the family of nonempty compact convex subsets of $X$ supplied with the Hausdorff metric, and let $B$ denote the closed unit ball in $X$. In [10] J. Markin proved that if $X$ is a (real) Hilbert space, if $\varphi: X \rightarrow \mathscr{K}(X)$ is a nonexpansive mapping (that is, $D(\varphi(x), \varphi(y)) \leqq\|x-y\|$ for all $x, y \in X$ ), and if $\varphi(x) \subset B$ for every $x \in B$, then $\varphi$ has a fixed point in $B$. Subsequently, E. Lami Dozo [9] generalized this result. He proved that if $X$ is a Banach space which satisfies Opial's condition and if $C$ is a nonempty, weakly compact, convex subset of $X$, then every nonexpansive setvalued mapping defined on $C$ whose values are nonempty compact subsets of $C$ possesses a fixed point. Application of Corollary 1 to Lami Dozo's approach yields the improvement of his result given below.

THEOREM 2. Let $X$ be a Banach space which satisfies Opial's condition, $H$ a closed convex subset of $X$, and $K$ a nonempty, weakly compact, convex subset of $H$. Let $T$ be a nonexpansive point-to-set transformation on $K$ into the nonempty compact subsets of $H$, and suppose $T x \subset K$ whenever $x \in \partial_{H} K$. Then $T$ has a fixed point in $K$.

Proof. It is readily seen that we may assume, without loss of generality, that $0 \in K$. Choose a sequence $\left\{r_{n}\right\}$ of real numbers, $0<$ $r_{n}<1$, such that $r_{n} \rightarrow 1$ as $n \rightarrow \infty$. For each $n, r_{n} T$ is a point-to-set contraction mapping from $K$ to the nonempty compact subsets of $H$. Furthermore, if $x \in \partial_{H} K$ then $r_{n} T x \subset K$ because $0 \in K$ and $K$ is convex. By Corollary 1 , it follows that for each $n, r_{n} T$ has a fixed point in $K$; say $x_{n} \in r_{n} T x_{n} \cap K, n=1,2, \cdots$. Hence $x_{n} / r_{n} \in T x_{n}$, and thus $x_{n}\left(1-1 / r_{n}\right) \in x_{n}-T x_{n}=(I-T) x_{n}$. Since $\left\{x_{n}\right\} \subset K$ and $K$ is weakly compact, it follows that $\left\{x_{n}\right\}$ has a weakly convergent subsequence, and we may merely assume $\left\{x_{n}\right\}$ itself converges weakly, say to $x_{0}$. Furthermore, since $\left\{x_{n}\right\}$ is bounded,

$$
w_{n}=x_{n}\left(1-1 / r_{n}\right) \longrightarrow 0 \text { strongly. }
$$

Following the argument of Lami Dozo, we show $0 \in(I-T) x_{0}$ and conclude $x_{0}$ is a fixed point of $T$.

Since $w_{n} \in(\mathrm{I}-T) x$ we may write $w_{n}=x_{n}-u_{n}$ where $u_{n} \in T x_{n}$. Thus

$$
D\left(T x_{n}, T x_{0}\right) \leqq\left\|x_{n}-x_{0}\right\|,
$$

and $u_{n} \in T x_{n}$ implies existence of $\bar{u}_{n} \in T x_{0}$ such that

$$
\left\|u_{n}-\bar{u}_{n}\right\| \leqq D\left(T x_{n}, T x_{0}\right) \text {. }
$$

Thus, 


$$
\left\|u_{n}-\bar{u}_{n}\right\| \leqq\left\|x_{n}-x_{0}\right\|
$$

It follows that

$$
\begin{aligned}
\liminf _{n \rightarrow \infty}\left\|x_{n}-x_{0}\right\| & \geqq \liminf _{n \rightarrow \infty}\left\|u_{n}-\bar{u}_{n}\right\| \\
& =\liminf _{n \rightarrow \infty}\left\|x_{n}-w_{n}-\bar{u}_{n}\right\| .
\end{aligned}
$$

Now, since $\left\{\bar{u}_{n}\right\}$ is contained in the compact set $T x_{0}$, we may suppose subsequences again have been chosen so that $\left\{\bar{u}_{n}\right\}$ converges strongly, say to $u_{0} \in T x_{0}$. Therefore,

$$
\begin{aligned}
\liminf _{n \rightarrow \infty} \| & x_{n}-w_{n}-\bar{u}_{n} \| \\
= & \liminf _{n \rightarrow \infty}\left\|x_{n}-w_{n}-\bar{u}_{n}+u_{0}-u_{0}\right\| \\
\geqq & \liminf _{n \rightarrow \infty}\left[\left\|x_{n}-u_{0}\right\|-\left\|w_{n}\right\|-\left\|\bar{u}_{n}-u_{0}\right\|\right] \\
\geqq & \liminf _{n \rightarrow \infty}\left\|x_{n}-u_{0}\right\|+\liminf _{n \rightarrow \infty}\left(-\left\|w_{n}\right\|\right) \\
& \quad+\liminf _{n \rightarrow \infty}\left(-\left\|\bar{u}_{n}-u_{0}\right\|\right) \\
= & \liminf _{n \rightarrow \infty}\left\|x_{n}-u_{0}\right\| .
\end{aligned}
$$

Thus we have shown:

$$
\liminf _{n \rightarrow \infty}\left\|x_{n}-x_{0}\right\| \geqq \liminf _{n \rightarrow \infty}\left\|x_{n}-u_{0}\right\| \text {. }
$$

Since $x_{n} \rightarrow x_{0}$ weakly, we have, by Opial's condition, $x_{0}=u_{0}$. But $u_{0} \in T x_{0}$ so we have the desired result.

3. Pseudo-contractive mappings. We include an application of Corollary 2 which generalizes a theorem of Kirk in [7].

In [5], F. Browder introduced the following definition: Let $X$ be a Banach space and $D \subset X$. A mapping $U: D \rightarrow X$ is said to be pseudocontractive if for all $u, v \in D$ and all $r>0$,

$$
\|u-v\| \leqq\|(1+r)(u-r)-r(U(u)-U(v))\| \text {. }
$$

Pseudo-contractive mappings are characterized by the property: $U$ is pseudo-contractive if and only if $I-U$ is accretive (see [5], Proposition 1). It is easily seen that these mappings include the nonexpansive mappings.

The approach of [7], showing how fixed point theorems for pseudocontractive mappings may be derived from the fixed point theory of nonexpansive mappings, may be modified to obtain the following:

Theorem 3. Let $X$ be a reflexive Banach space, $H$ a closed convex subset of $X$, and $K$ a nonempty, bounded, closed, convex subset 
of $H$ which posseses normal structure. Let $U$ be a Lipschitzian pseudo-contractive mapping of $K$ into $H$ such that $U(x) \in K$ when $x \in$ $\partial_{H} K$. Then $U$ has a fixed point in $K$.

The concept of "normal structure" [2] enters here only so that the theorem of Kirk [6] may be applied. In particular, if $X$ is uniformly convex, or if $K$ is compact, then $K$ always possesses normal structure.

Proof of Theorem 3. Since $U$ is Lipschitzian there exists a number $\lambda, 0<\lambda<1$, such that $\lambda U$ is a contraction mapping. Taking $\lambda=$ $r /(1+r)$, (1) implies that the mapping $T_{\lambda}=I-\lambda U$ satisfies

$$
\| T_{\lambda}\left(u-T_{\lambda}(v)\|\geqq(1-\lambda)\| u-v \|, \quad u, v \in K .\right.
$$

Hence $(1-\lambda) T_{\lambda}^{-1}$ is a nonexpansive mapping on its domain. Now let

$$
y^{*} \in(1-\lambda) K=\{(1-\lambda) y: y \in K\},
$$

and consider the mapping $\bar{U}_{\lambda}: K \rightarrow X$ defined by

$$
\bar{U}_{\lambda}(x)=\lambda U(x)+y^{*}, \quad x \in K .
$$

For $x \in \partial_{H} K$, then $U(x) \in K$, hence

$$
\bar{U}_{\lambda}(x)=\lambda U(x)+(1-\lambda) y^{\prime}
$$

for some $y^{\prime} \in K$, and this implies $\bar{U}_{\lambda}(x) \in K$. Thus $\bar{U}_{\lambda}$ is a contraction mapping satisfying the assumptions of Corollary 2, so there is a point $x^{*} \in K$ which is fixed under $\bar{U}_{\lambda}$. Hence

$$
\begin{gathered}
\lambda U\left(x^{*}\right)+y^{*}=x^{*} ; \\
(I-\lambda U) x^{*}=y^{*} .
\end{gathered}
$$

Therefore $T_{\lambda}(K) \supset(1-\lambda) K$, which implies

$$
(1-\lambda) T_{\lambda}^{-1}:(1-\lambda) K \longrightarrow(1-\lambda) K .
$$

By the theorem of Kirk [6] the mapping $(1-\lambda) T_{\lambda}^{-1}$ has a fixed point $z \in(1-\lambda) K$. Letting $z=(1-\lambda) z^{*}$ one quickly sees that $U\left(z^{*}\right)=z^{*}$ (cf. [7]).

The above theorem also extends Theorem 2.1 of [8], which was proved by a different method, from the class of nonexpansive mappings to the class of Lipschitzian pseudo-contractive mappings.

The connection between pseudo-contractive and nonexpansive mappings has recently been further refined. R. E. Bruck has made the interesting observation that if $C$ is a closed convex set which has the fixed point property for nonexpansive mappings, and if $U: C \rightarrow C$ 
is a Lipschitzian local pseudocontraction, then $U$ always has a fixed point.

4. A theorem in Hilbert space. The assumptions on the mapping of Theorem 2 may be considerably weakened if $X$ is a Hilbert space and $K$ a closed ball centered at the origin. Here we give a theorem which was proved for point-to-point mappings by Browder [3, Theorem 3].

THEOREM 4. Let $\mathscr{H}$ be a Hilbert space and $B$ the closed unit ball in $\mathscr{H}$. Suppose $\varphi$ is a nonexpansive mapping from $B$ into the nonempty compact subsets of $\mathscr{H}$. If $\varphi$ satisfies the condition:

(i) $\lambda x \notin \varphi(x)$ if $x \in \partial B$ and $\lambda>1$, then $\varphi$ has a fixed point in $B$.

Proof. We use the fact that "radial projection" in Hilbert spaces is nonexpansive. For $x \in B$, let

$$
\bar{\varphi}(x)=\{z: z \in \varphi(x) \text { and }\|z\| \leqq 1\} \cup\{z /\|z\|: z \in \varphi(x) \text { and }\|z\|>1\} \text {. }
$$

Then $\bar{\varphi}$ is also a nonexpansive mapping from $B$ into the nonempty compact subsets of $B$. By Theorem 2 (or the result of Lami Dozo) there exists $x_{0} \in B$ such that $x_{0} \in \bar{\varphi}\left(x_{0}\right)$. Since $\lambda x_{0} \notin \varphi\left(x_{0}\right)$ if $x_{0} \in \partial B$ and $\lambda>1$, it follows that $x_{0} \in \varphi\left(x_{0}\right)$.

\section{REFERENCES}

1. L. M. Blumenthal, Theory and applications of distance geometry, The Clarendon Press, Oxford, 1953.

2. M. S. Brodskii and D. P. Milman, On the center of a convex set, Dokl. Akad. Nauk SSSR (N. S.), 59 (1948), 837-840.

3. F. E. Browder, Fixed-point theorems for noncompact mappings in Hilbert space, Proc. Nat. Akad. Sci., 53 (1965), 1272-1276.

4. - Fixed point theorems for nonlinear semicontractive mappings in Banach spaces, Arch. Rational Mech. Anal., 21 (1966), 259-269.

5. - Nonlinear mappings of nonexpansive and accretive type in Banach spaces, Bull. Amer. Math. Soc., 73 (1967), 875-881.

6. W. A. Kirk, A fixed point theorem for mappings which do not increase distances, Amer. Math. Monthly, 72 (1965), 1004-1006.

7. - Remarks on pseudo-contractive mappings, Proc. Amer. Math. Soc., 25 (1970), 820-823.

8. - Fixed point theorems for nonlinear nonexpansive and generalized contraction mappings Pacific J. Math., 38 (1971), 89-94.

9. E. Lami Dozo, Opérateurs non-expansifs, P-compacts et propriétés géométriques de la norme, Thèse Univ. Libre de Bruxelles, 1970.

10. J. T. Markin, A fixed point theorem for set valued mappings, Bull. Amer. Math. Soc., 74 (1968), 639-640.

11. S. B. Nadler, Jr., Multi-valued contraction mappings, Pacific J. Math., 30 (1969), 475-488. 
12. Z. Opial, Weak convergence of the sequence of successive approximations for nonexpansive mappings, Bull. Amer. Math. Soc., 73 (1967), 591-597.

Received August 24, 1971. Research of the second author supported by National Science Foundation Grant GP 18045.

UNIVERSITY OF IOWA 


\section{PACIFIC JOURNAL OF MATHEMATICS}

\section{EDITORS}

\author{
H. SAMELSON \\ Stanford University \\ Stanford, California 94305 \\ C. R. HOBBY \\ University of Washington \\ Seattle, Washington 98105
}

\section{J. DugundjI}

Department of Mathematics University of Southern California Los Angeles, California 90007

\section{RICHARD ARENS}

University of California

Los Angeles, California 90024

\section{ASSOCIATE EDITORS}
E. F. BECKENBACH
B. H. NeumanN
F. WOLF
K. YosHIDA

\section{SUPPORTING INSTITUTIONS}

\author{
UNIVERSITY OF BRITISH COLUMBIA \\ CALIFORNIA INSTITUTE OF TECHNOLOGY \\ UNIVERSITY OF CALIFORNIA \\ MONTANA STATE UNIVERSITY \\ UNIVERSITY OF NEVADA \\ NEW MEXICO STATE UNIVERSITY \\ OREGON STATE UNIVERSITY \\ UNIVERSITY OF OREGON \\ OSAKA UNIVERSITY
}

\author{
UNIVERSITY OF SOUTHERN CALIFORNIA \\ STANFORD UNIVERSITY \\ UNIVERSITY OF TOKYO \\ UNIVERSITY OF UTAH \\ WASHINGTON STATE UNIVERSITY \\ UNIVERSITY OF WASHINGTON \\ ${ }^{*} \stackrel{*}{*}{ }^{*}$
AMERICAN MATHEMATICAL SOCIETY
NAVAL WEAPONS CENTER
}

The Supporting Institutions listed above contribute to the cost of publication of this Journal, but they are not owners or publishers and have no responsibility for its content or policies.

Mathematical papers intended for publication in the Pacific Journal of Mathematics should be in typed form or offset-reproduced, (not dittoed), double spaced with large margins. Underline Greek letters in red, German in green, and script in blue. The first paragraph or two must be capable of being used separately as a synopsis of the entire paper. The editorial "we" must not be used in the synopsis, and items of the bibliography should not be cited there unless absolutely necessary, in which case they must be identified by author and Journal, rather than by item number. Manuscripts, in duplicate if possible, may be sent to any one of the four editors. Please classify according to the scheme of Math. Rev. Index to Vol. 39. All other communications to the editors should be addressed to the managing editor, Richard Arens, University of California, Los Angeles, California, 90024.

50 reprints are provided free for each article; additional copies may be obtained at cost in multiples of 50 .

The Pacific Journal of Mathematics is published monthly. Effective with Volume 16 the price per volume (3 numbers) is $\$ 8.00$; single issues, $\$ 3.00$. Special price for current issues to individual faculty members of supporting institutions and to individual members of the American Mathematical Society: $\$ 4.00$ per volume; single issues $\$ 1.50$. Back numbers are available.

Subscriptions, orders for back numbers, and changes of address should be sent to Pacific Journal of Mathematics, 103 Highland Boulevard, Berke'ey, California, 94708.

PUBLISHED BY PACIFIC JOURNAL OF MATHEMATICS, A NON-PROFIT CORPORATION

Printed at Kokusai Bunken Insatsusha (International Academic Printing Co., Ltd.), 270, 3-chome Totsuka-cho, Shinjuku-ku, Tokyo 160, Japan. 


\section{Pacific Journal of Mathematics}

\section{Vol. 43, No. $3 \quad$ May, 1972}

Max K. Agoston, An obstruction to finding a fixed point free map on a manifold.... 543

Nadim A. Assad and William A. Kirk, Fixed point theorems for set-valued mappings

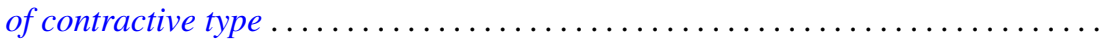

John Winston Bunce, Characterizations of amenable and strongly amenable

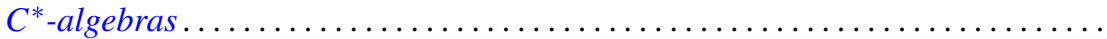

Erik Maurice Ellentuck and Alfred Berry Manaster, The decidability of a class of

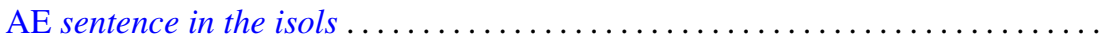

U. Haussmann, The inversion theorem and Plancherel's theorem in a Banach

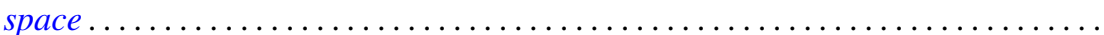

Peter Lawrence Falb and U. Haussmann, Bochner's theorem in infinite dimensions.

Peter Fletcher and William Lindgren, Quasi-uniformities with a transitive base ..... Dennis Garbanati and Robert Charles Thompson, Classes of unimodular abelian

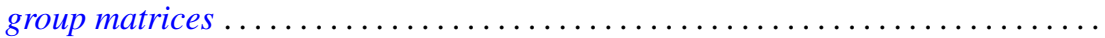

Kenneth Hardy and R. Grant Woods, On c-realcompact spaces and locally bounded normal functions

Manfred Knebusch, Alex I. Rosenberg and Roger P. Ware, Grothendieck and Witt rings of hermitian forms over Dedekind rings .......................

George M. Lewis, Cut loci of points at infinity.

Jerome Irving Malitz and William Nelson Reinhardt, A complete countable $L_{\omega_{1}}^{Q}$ theory with maximal models of many cardinalities . . . . . . . . . . . . . . . . .

Wilfred Dennis Pepe and William P. Ziemer, Slices, multiplicity, and Lebesgue

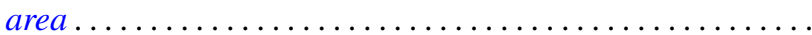

Keith Pierce, Amalgamating abelian ordered groups . .

Stephen James Pride, Residual properties of free groups . . . . . . . . . . . . . 725

Roy Martin Rakestraw, The convex cone of n-monotone functions .

T. Schwartzbauer, Entropy and approximation of measure preserving transformations .

Peter F. Stebe, Invariant functions of an iterative process for maximization of a polynomial...

Kondagunta Sundaresan and Wojbor Woyczynski, L-orthogonally scattered

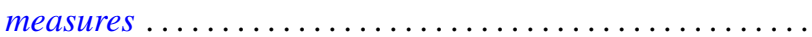

Kyle David Wallace, $C_{\lambda}$-groups and $\lambda$-basic subgroups $\ldots \ldots \ldots$

Barnet Mordecai Weinstock, Approximation by holomorphic functions on certain

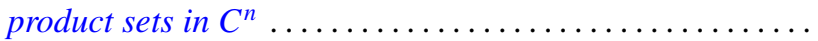

Donald Steven Passman, Corrections to: "Isomorphic groups and group rings”.

Don David Porter, Correction to: "Symplectic bordism, Stiefel-Whitney numbers, and a Novikov resolution"

John Ben Butler, Jr., Correction to: “Almost smooth perturbations of self-adjoint operators".

Constantine G. Lascarides, Correction to: "A study of certain sequence spaces of Maddox and a generalization of a theorem of Iyer" ...... ...

George A. Elliott, Correction to: "An extension of some results of takesaki in the reduction theory of von neumann algebras" ......................... 